\title{
Seasonal changes in the level and diel pattern of activity in the European lobster Homarus gammarus
}

\author{
I. P. Smith*, K. J. Collins, A. C. Jensen \\ School of Ocean and Earth Science, University of Southampton, Southampton Oceanography Centre, \\ European Way, Southampton SO14 3ZH, United Kingdom
}

\begin{abstract}
European lobsters are large, mobile crustaceans of ecological and commercial significance. Until recently, the lack of a reliable technique for long-term, in situ monitoring of activity has hindered study of seasonal variation in activity and its determinants. Electromagnetic telemetry has been used to measure seasonal changes in locomotor activity and body movements of lobsters on an artificial reef in Poole Bay, southern England. Both measures of activity showed marked seasonal variation, related primarily to water temperature, with greatest activity in late summer and minimum values in winter. Subsidiary effects of water movement and seabed illumination were also indicated. Throughout the spring and summer, excursions outside shelter were almost exclusively nocturnal, with movement peaking in the early part of the night. Body movements followed a similar pattern, but with less abrupt changes, suggesting a degree of activity within shelters during the day. Diel timing of lobster activity appeared to be mainly governed exogenously by light level, since the length of the nocturnal active period and the timing of the activity peak varied seasonally with the times of sunset and sunrise, and there was a relative increase in diurnal activity during periods of low seabed light levels caused by increased turbidity. During low temperatures in mid to late winter, activity was low throughout the $24 \mathrm{~h}$ cycle. These findings suggest that there are likely to be significant seasonal changes in the relationship between fishing effort and fishing mortality that need to be taken into account in lobster stock assessment.
\end{abstract}

KEY WORDS: Lobster · Homarus gammarus - Electromagnetic telemetry · Season - Movements · Activity rhythms

\section{INTRODUCTION}

Degree of mobility and timing of activity are fundamental aspects of animal behaviour linked to the nature of habitat use and the frequency of encounters with conspecifics, predators and prey. Movement patterns of mobile species are important in determining the distribution of individuals in space and time and can therefore affect density-dependent population dynamics (Sutherland 1996) and the structure of the associated community (Begon et al. 1990). Variation in locomotor activity can also influence the reliability of

\footnotetext{
•E-mail: philip.smith@soc.soton.ac.uk
}

population census techniques, by altering the proportion of individuals in the sampling area likely to be detected with a given level of sampling effort (Greenwood 1996). In commercial fisheries, information about the size of the fishable stock is required for rational fisheries management and this is often based on catch per unit of fishing effort (Gulland 1983). Stock assessment based on catch per unit effort needs to take account of behavioural changes in 'catchability', which in turn requires an understanding of the determinants of movement patterns and other aspects of activity that may influence probability of capture (Arnold et al. 1990).

European lobsters, Homarus gammarus (L.), are large, mobile crustaceans of ecological and commer- 
cial importance, yet there is a lack of information about seasonal changes in their behaviour, due in part to the difficulties of conducting long term observational studies in situ. Intensive diving studies of American lobsters $H$. americanus have revealed details about seasonal changes in activity, usually by scan sampling (Martin \& Bateson 1993), which provides discrete records of the behaviour of individuals as they are encountered by divers (review by Cooper \& Uzmann 1980, Ennis 1984b, Karnofsky et al. 1989a). Extended diving studies of $H$. gammarus carried out in western Sweden provided some qualitative information about diel and seasonal patterns in activity, but the primary aims of these studies were to describe habitat choice (Dybern et al. 1967, Dybern 1973) and diet composition (Hallbäck \& Waren 1972), and the majority of observations were made during the day in summer and autumn

Restrictions on the underwater endurance of divers and the disturbance they cause, particularly at night, limit the practicability of other diver-based behavioural sampling techniques that would provide more detail about individual behaviour in the field, such as focal animal sampling (Martin \& Bateson 1993). This technique has been used successfully by divers in some circumstances (e.g. O'Neill \& Cobb 1979, Herrnkind 1980, Karnofsky et al. 1989a), but in temperate waters, it is usually not possible to maintain a constant level of diving effort or effectiveness of visual observations throughout the year, owing particularly to adverse conditions in winter (Gamble 1984).

Acoustic tracking is a form of focal animal sampling, without some of the limitations of visual observations, which has been used to study movement patterns of Homarus americanus and Homarus gammarus (e.g. Lund \& Lockwood 1970, Arnold et al. 1990, Collins \& Jensen 1992, unpubl. studies reviewed by Lawton \& Lavalli 1995). However, tracking with a hand-held directional hydrophone is labour intensive and weather-dependent, while automated position fixing with a hydrophone array is hampered by reflection and attenuation of ultrasound by the irregular rocky substratum typical of adult Homarus spp. habitat (Urquhart \& Smith 1992, van der Meeren 1997). In addition, the power requirements of acoustic transmitters restrict the lifetime of tags that can be carried by small animals (Wolcott 1995). To date, limited information has been published from acoustic tracking of Homarus spp., compared with similar studies of other crustaceans that inhabit less obstructed seabed or that undertake more extensive movements (e.g. Chapman et al. 1975, Herrnkind et al. 1975, Hall et al. 1991, Stone et al. 1992, Hines et al. 1995).

Electromagnetic telemetry (Ramm 1980) is not impeded by irregular seabed topography and the power requirement of transmitters is relatively low, permitting long transmitter life and extended monitoring periods. However, the range of detection is shorter than in acoustic tracking and reception by electromagnetic inductive coupling is not directional, so the position of transmitters is determined by presence within the detection zone of individual aerials (Wolcott 1995) This rather low-resolution positional information can be supplemented by encoding other behavioural, physiological or environmental measurements in the tag signals (Collins 1996). Smith et al. (1998) reported results of electromagnetic telemetry of Homarus gammarus on an artificial reef in Poole Bay, southern England, which revealed diel patterns of activity in late summer and autumn and provided preliminary data on seasonal changes during the onset of winter. The present paper analyses changes in the level of activity and in the diel pattern over an annual cycle, in relation to seasonal and environmental variables and lobster attributes.

\section{MATERIALS AND METHODS}

Study site. Lobster activity was studied at an artificial reef in Poole Bay on the south coast of England. The reef was constructed in 1989 and consists of 8 piles of blocks $(0.4 \times 0.2 \times 0.2 \mathrm{~m})$ made of concrete or cement-stabilised pulverised fuel ash (Collins et al 1991). The piles, subsequently referred to as reef units are approximately $5 \mathrm{~m}$ in diameter and $1 \mathrm{~m}$ high and are arranged in 2 rows of 4 , aligned east-west, occupying an area of sedimentary seabed $15 \times 35 \mathrm{~m}$ at a mean water depth of $12 \mathrm{~m}$, with mean tidal range of $0.5 \mathrm{~m}$ (neaps) to $1.7 \mathrm{~m}$ (springs). The artificial reef is located next to the protected zone of a historic wreck site. On the basis of frequent visits to the site and the vigilance of local boat operators involved with the project, there was no evidence of non-scientific lobster fishing or diving activities on the artificial reef during the study period.

Telemetry system. An electromagnetic telemetry system was used to monitor lobster activity from 9 August 1996 to 28 September 1997. Technical details of the telemetry system were given by Collins (1996). Briefly, lobsters were fitted with electronic tags that transmitted a coded electromagnetic signal $(32.7 \mathrm{kHz})$ at $30 \mathrm{~s}$ intervals. Each transmission conveyed identity and a measure of body movement (pitching and rolling), derived from an integral tilt switch and coded as an integer 'activity level' $(0-8)$. Tag signals were detected at 10 min intervals by electromagnetic inductive coupling with $5 \mathrm{~m}$ diameter loop aerials laid on the seabed around each of the reef units and connected to a central receiver and data logger. Movements 
between reef units by lobsters were indicated by detection of their tags with different aerials. The data logger also recorded water temperature, light level, hydrostatic pressure, current speed and significant wave height (details of sensors in Smith et al. 1998). The data logger and battery packs were swapped by divers at intervals of up to $4 \mathrm{wk}$.

Lobster capture and tagging. Parlour pots (Lovewell et al. 1988) placed adjacent to each of the 8 reef units were baited with whole mackerel, usually at around 08:30 to 09:30 h local time, and left for 1 or $2 \mathrm{~d}$ before divers removed lobsters and brought them to the surface in individual net bags at a similar time of day. A few lobsters were also caught by hand. Lobsters were measured and a transmitting tag was attached to the dorsal surface of the cephalothorax with quick-setting epoxy resin, after drying the carapace with propanone. The tag was attached with the integral tilt switch level and with its long axis at a horizontal angle of $45^{\circ}$ to the long axis of the lobster's body, so that pitch and roll would be detected equally. Lobsters were also tagged with numbered plastic tags (T-bar internal anchor tag and streamer tag, Hallprint Pty. Ltd, Holden Hill, South Australia) inserted between the cephalothorax and first abdominal segment so that they were retained through ecdysis. Divers returned tagged lobsters to the reef unit where they were caught within $1 \mathrm{~h}$ of capture. Lobsters were maintained in cool, dark, moist conditions during the tagging procedure, which involved aerial exposure of approximately $10 \mathrm{~min}$.

Forty-one lobsters (21 females, 20 males) of carapace length 72 to $139 \mathrm{~mm}$ were tagged, of which 14 had been previously tagged with T-bar and streamer tags at the artificial reef. Up to 11 individuals were monitored simultaneously, 16 were tracked for more than 1 mo (the tilt switch failed in one of these) and 4 (1 male, 3 females) were tracked for over 6 mo. Five individuals were re-tagged after recapture following loss of the electromagnetic tag.

Some periods of data loss resulted from damage to the aerial array, thought to have been caused by recreational craft dragging their anchors. The lead to 1 aerial was severed on 4 November 1996 and another on 15 February 1997. Fortunately, the lobsters present on the site during the period of damage were detected by other aerials. The aerial array was repaired when weather and underwater conditions permitted on 26 March 1997, but the replacement array was faulty and was itself replaced on 9 May 1997. As a result, no reliable movement or activity data were obtained in April 1997. An aerial lead was again severed on 22 June 1997 and replaced on 11 July 1997.

Statistical analysis. The influence of environmental variables on the movement of lobsters between units of the artificial reef was assessed by multiple regression of daily number of movements per lobster (square root transformed) on daily means of water temperature, mid-day light level (averaged over 11:00 to 13:00 h GMT), significant wave height (Earle \& Bishop 1984), tidal range and day length. Lobster identity was used as a blocking variable and autocorrelation was corrected with the Cochrane-Orcutt procedure (Neter et al. 1996). Daily mean activity level (derived from the tilt switch, not transformed) was analysed similarly.

Differences in mean daily number of movements (square root transformed) and mean activity level between males and females were tested for each month in which there were data from more than 1 male and female lobster by analysis of variance (ANOVA), with lobster identity nested within sex (male or female). A similar analysis was performed for movements and activity in relation to 2 size categories: less than and greater than $95 \mathrm{~mm}$ carapace length (the number of categories was limited by the available sample size and the division was chosen to give approximately equal numbers of individuals in each category).

The average diel pattern of movements between units of the artificial reef was assessed in each month for which there were sufficient movements by calculating for each lobster the percentage of the monthly total number of movements by that individual occurring in each hour of the day. Variation in percentage of movements (Freeman-Tukey arcsine-transformed) was tested in relation to hour of the day for each month by a randomized block ANOVA, with lobster identity as the blocking variable. A similar analysis was performed for mean hourly activity level (not transformed).

\section{RESULTS}

\section{Environmental conditions}

The major seasonal changes in measured environmental variables were in water temperature, light level and wave height. Water temperature peaked in late August and reached a minimum in early February, with an annual range of $16^{\circ} \mathrm{C}$ (Fig. 1). Wave height was very variable with peak wave heights occurring for only short periods of time. Wave height was generally greater during the winter as a result of higher wind speeds. Light level on the sea bed at mid-day (averaged between 11:00 and 13:00 h GMT) declined to low levels from November to April owing mainly to reduced water transparency, low sun altitude and increased cloud cover. Increases in wave height were associated with a rapid decline in mid-day illumination at the seabed. Increased sea surface roughness increases the amount of light reflected at the surface, 

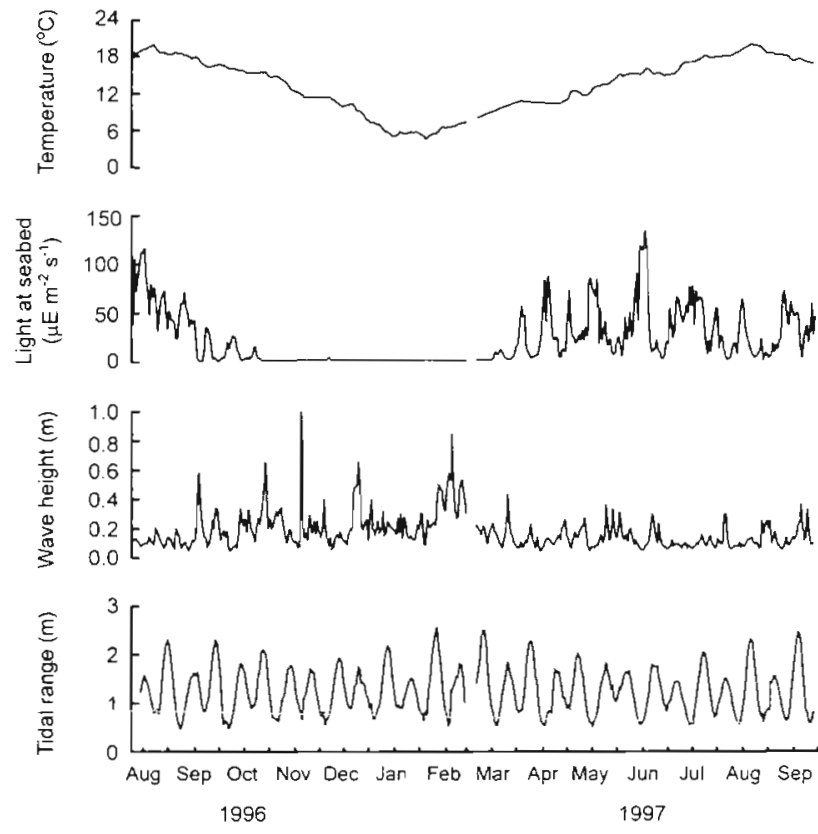

Fig. 1 Environmental conditions during the study period Temperature and tidal range are plotted as daily means, light level is averaged over the period 11:00 to 13:00 $\mathrm{h}$ GMT and wave height is plotted as 6-hourly measurements

but the effect of waves on illumination was largely due to increased turbidity. Tidal range, derived from depth measurements, reflected the semilunar cycle of spring and neap tides and influenced maximum tidal current speeds experienced at the seabed.

\section{Tag reliability and lobster emigration}

Of the 46 electromagnetic tags fitted to lobsters, 20 were functioning after the lobster was recaptured, the tag was shed, or the study ended, 6 were recovered inoperative from recaptured lobsters or the seabed and 20 were lost as a result of the lobster moving outside the range of the telemetry system, tag failure, or unreported recapture. Unless the lobster or the tag was recovered, it was not possible to determine whether signal loss was due to tag failure or the animal leaving the study site. Three tagged lobsters were caught away from the study site by commercial fishermen. Assuming a similar tag failure rate for the 'lost' tags as those accounted for (23\%), a minimum of approximately 15 other tagged individuals may have moved away from the site. The proportion of tags whose signal was lost within 2 wk of release was lower in those attached to lobsters that had been conventionally tagged at the site previously $(21.4 \%, \mathrm{n}=14)$ than in those attached to lobsters tagged for the first time during the present study $\left(70.4 \%, \mathrm{n}=27, G_{1}=8.88\right.$, $p=0.003$ ), suggesting a greater tendency for previously untagged lobsters to leave the site. The proportion of tags whose signal was lost was not significantly related to the sex $\left(G_{1}=0.61, \mathrm{p}=0.43\right)$ or size $\left(F_{1,38}=\right.$ $1.70, p=0.20$ ) of lobster to which they were attached

\section{Movements between reef units}

There was a seasonal pattern in movements between reef units by lobsters (Fig. 2). Frequency of movement was greatest in summer and declined during the autumn. Few inter-reef unit movements were recorded from late December until early May, when lobsters began to move between reef units more frequently again. Despite the lack of inter-reef unit movement in winter, body movements detected by the tilt switch and resumption of translocational movement in spring indicated that the lobsters being monitored were alive. The daily number of inter-reef unit movements per lobster was significantly, positively related to water temperature $\left(F_{1.1732}=109.5, \mathrm{p}<0.0005\right)$ and more weakly, negatively related to tidal rangc $\left(F_{1,1,32}=4.47\right.$. $\mathrm{p}=0.035$ ), but was not significantly related to mid-day light level $\left(F_{1,1732}=0.145, p=0.703\right)$, wave height $\left(F_{1,1732}=0.642, \mathrm{p}=0.423\right)$, or day length $\left(F_{1,1732}=0.022\right.$, $\mathrm{p}=0.881)$.

In most months for which there were sufficient movement data for both sexes, there was no significant difference between males and females in the mean daily number of inter-reef unit movements per lobster (Table 1). In May (5 females, 2 males monitored), males exhibited significantly greater movement than females. In most months, there was also no significant difference between size categories in the mean number of inter-reef unit movements per day per lobster, although smaller lobsters exhibited more frequent movement than larger individuals in September and November (Table 2).

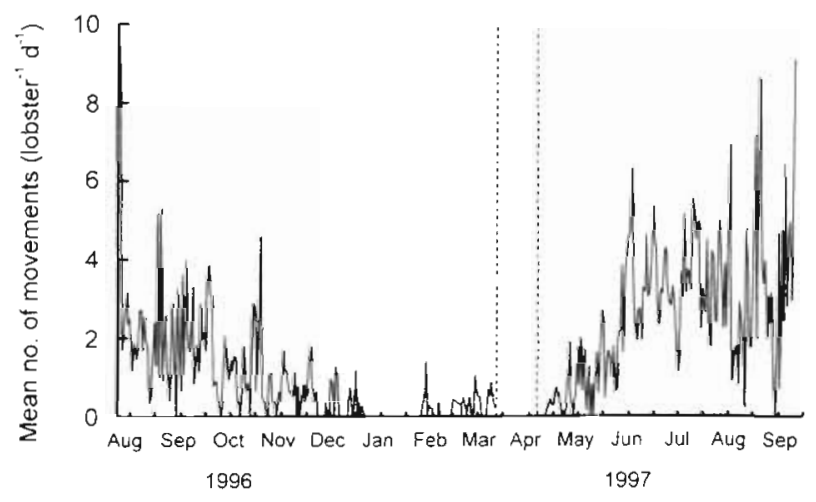

Fig. 2. Daily mean number of movements between reef units per lobster in relation to time of year. Vertical dashed lines indicate a period when the telemetry system was damaged 
Table 1. Analysis of variance of daily number of inter-reef unit movements and daily mean activity level in relation to sex.

\begin{tabular}{|c|c|c|c|c|c|c|}
\hline \multirow[t]{2}{*}{ Month } & \multicolumn{3}{|c|}{ Movements } & \multicolumn{3}{|c|}{ Activity } \\
\hline & $F$ & $\mathrm{df}$ & $p$ & $F$ & df & $\mathrm{p}$ \\
\hline Feb & - & - & - & 0.334 & 1,3 & 0.604 \\
\hline Mar & - & - & - & 0.084 & 1,2 & 0.799 \\
\hline May & 9.888 & 1,5 & 0.026 & 0.529 & 1,5 & 0.499 \\
\hline Jun & 0.028 & 1,9 & 0.872 & 0.037 & 1.8 & 0.852 \\
\hline Jul & 0.180 & 1,9 & 0.681 & 1.239 & 1,9 & 0.294 \\
\hline Aug & 0.001 & 1,13 & 0.980 & 3.623 & 1,12 & 0.081 \\
\hline Sep & 2.581 & 1,9 & 0.143 & 1.465 & 1,7 & 0.265 \\
\hline
\end{tabular}

Throughout the spring and summer, inter-reef unit movements were predominantly nocturnal, peaking 1 to $3 \mathrm{~h}$ after sunset (Fig. 3, Table 3). From May to July and in October less than $8 \%$ of movements between reef units occurred during the day (sunrise to sunset), but in August, September and November, daytime movements were more frequent $(12,25$ and $27 \%$, respectively). In some months, there was a secondary increase in movement after the main post-dusk peak, before a return to low levels around dawn (Fig. 3). From December to April too few movements were recorded to assess any diel pattern.

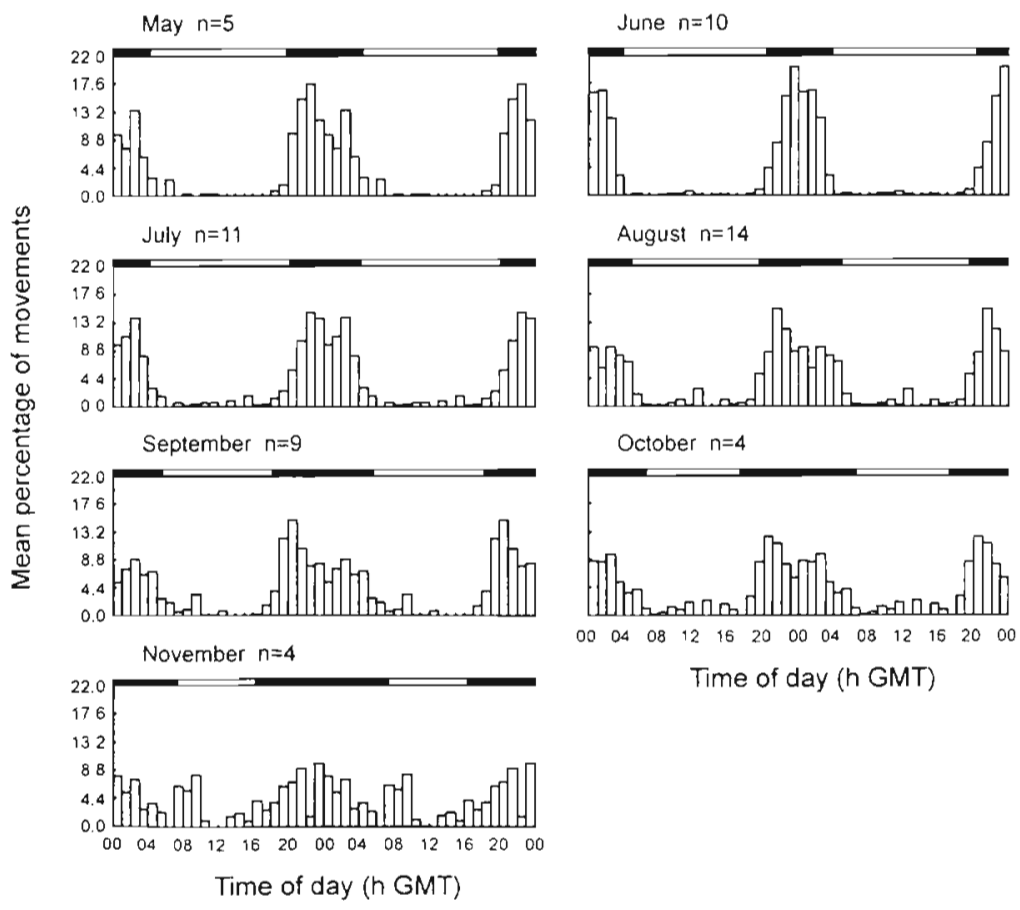

Fig. 3. Movements between reef units in relation to time of day in months when there was sufficient movement for analysis. Bars in each month represent the mean percentage of movements of the number of lobsters indicated. Two daily cycles are shown, for clarity. The black and white bars indicate the average periods of night and day, respectively
Table 2. Analysis of variance of daily number of inter-reef unit movements and daily mean activity level in relation to size category (less than or greater than $95 \mathrm{~mm} \mathrm{CL}$ )

\begin{tabular}{|c|c|c|c|c|c|c|}
\hline \multirow[t]{2}{*}{ Month } & \multicolumn{3}{|c|}{ Movements } & \multicolumn{3}{|c|}{ Activity } \\
\hline & $F$ & $\mathrm{df}$ & $\mathrm{p}$ & $F$ & df & $p$ \\
\hline Jan & - & - & - & 3.278 & 1,2 & 0.212 \\
\hline Feb & - & - & - & 0.534 & 1,3 & 0.518 \\
\hline Mar & - & - & - & 0.014 & 1,2 & 0.916 \\
\hline May & 0.032 & 1,5 & 0.864 & 1.240 & 1,5 & 0.316 \\
\hline Jun & 0.500 & 1,9 & 0.497 & 0.006 & 1,8 & 0.942 \\
\hline Jul & 4.150 & 1,9 & 0.072 & 0.062 & 1,9 & 0.809 \\
\hline Aug & 0.386 & 1,13 & 0.545 & 0.295 & 1,12 & 0.597 \\
\hline Sep & 10.975 & 1,9 & 0.008 & 2.959 & 1,8 & 0.142 \\
\hline $\mathrm{Oct}$ & 2.688 & 1,5 & 0.162 & 1.470 & 1,4 & 0.292 \\
\hline Nov & 43.636 & 1,3 & 0.007 & 0.001 & 1,2 & 0.979 \\
\hline Dec & - & - & - & 1.502 & 1,2 & 0.345 \\
\hline
\end{tabular}

\section{Activity}

As with inter-reef unit movements, daily mean activity (tilt switch data) varied seasonally (Fig. 4) and, of the measured environmental variables, was related most closely to water temperature $\left(F_{1,1635}=\right.$ $348.3, \mathrm{p}<0.0005)$. Activity level was also positively related to wave height $\left(F_{1,1535}=63.2, p<0.0005\right)$ and negatively related to mid-day illumination $\left(F_{1,1635}=13.4, \mathrm{p}<0.0005\right)$, but was not significantly related to tidal range $\left(F_{1,1635}=0.005, \mathrm{p}=0.945\right)$ or day length $\left\{F_{1,1635}=2.395, p=0.122\right)$. In months for which there were data from more than one of each sex, there was no significant difference in mean activity level between males and females (Table 1). Mean activity level also did not differ significantly between size categories (Table 2).

Since measurements of activity with the tilt switch did not rely on lobsters moving between aerials, it was possible to assess the diel pattern of activity in each month of the year, with the exception of April (Fig. 5). From March until October, there was a marked diel pattern resembling that of inter-reef unit movements, with peak activity usually in the early part of the night. In contrast to the frequency of inter-reef unit movements, however, activity began to increase several hours before sunset in some months and tended to decline gradually from the nocturnal maximum to a minimum at around midday. In No- 
Table 3. Analysis of variance of proportion of movements per hour (arcsine-transformed) and hourly mean activity level in relation to hour of day

\begin{tabular}{|c|c|c|c|c|c|c|}
\hline \multirow[t]{2}{*}{ Month } & \multicolumn{3}{|c|}{ Movements } & \multicolumn{3}{|c|}{ Activity } \\
\hline & $F$ & $\mathrm{df}$ & $\mathrm{p}$ & $F$ & $\mathrm{df}$ & $\mathrm{p}$ \\
\hline Jan & - & - & - & 1.086 & 23,68 & 0.383 \\
\hline Feb & - & - & - & 0.736 & 23,92 & 0.797 \\
\hline Mar & - & - & - & 2.187 & 23,46 & 0.012 \\
\hline May & 7.275 & 23,92 & $<0.0005$ & 2.550 & 23,115 & 0.001 \\
\hline Jun & 31.286 & 23,207 & $<0.0005$ & 6.471 & 23,230 & $<0.0005$ \\
\hline Jul & 13.786 & 23,228 & $<0.0005$ & 4.881 & 23,207 & $<0.0005$ \\
\hline Aug & 10.457 & 23,298 & $<0.0005$ & 3.467 & 23,299 & $<0.0005$ \\
\hline Sep & 6.337 & 23,167 & $<0.0005$ & 3.519 & 23,161 & $<0.0005$ \\
\hline Oct & 2.638 & 23,69 & 0.001 & 2.565 & 23,92 & 0.001 \\
\hline Nov & 2.080 & 23,69 & 0.010 & 1.291 & 23,69 & 0.207 \\
\hline Dec & - & - & - & 1.301 & 23,69 & 0.200 \\
\hline
\end{tabular}

vember this diel pattern became less evident and from December to February activity was low and not significantly related to time of the day (Table 3). It is noteworthy that minimum activity levels during the day in summer were greater than maximum values at any time of day in mid-winter.

\section{DISCUSSION}

Using electromagnetic telemetry, it has been possible to monitor locomotor activity and body movements of individual lobsters for long periods (over 11 mo in 1 case). Translocational movements could only be monitored on a small scale, but foraging and social interactions are largely accomplished within the scope of short range movements in a variety of species of lobster (Cooper \& Uzmann 1980, Herrnkind 1980, Ennis 1984b, Karnofsky et al. 1989b), including Homarus gammarus (Dybern et al. 1967). Previous diver observations of individually marked lobsters at the artificial reef in Poole Bay indicated that over $30 \%$ remained within this small site for at least $30 \mathrm{~d}$ after tagging (Jensen et al. 1994) and some individuals have been recorded there repeatedly for more than 4 yr. The electromagnetic telemetry system used in the present study therefore probably provided information on a spatial scale appropriate to much of the activity of adult $H$. gammarus.

Longer range movements do occur, however, so it should be borne in mind that the activity patterns described in the present study may not be representative of more wide-ranging individuals. Although the telemetry system could not track movements away from the artificial reef, some infor-

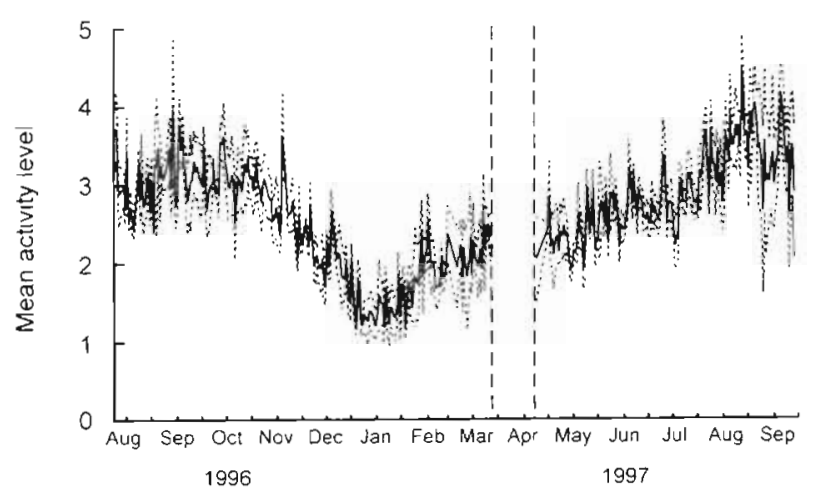

Fig. 4. Daily mean activity level (solid line, see 'Materials and methods: Telemetry system' for derivation) with standard errors (dotted lines) in relation to time of year. Vertical dashed lines indicate a period when the telemetry system was damaged
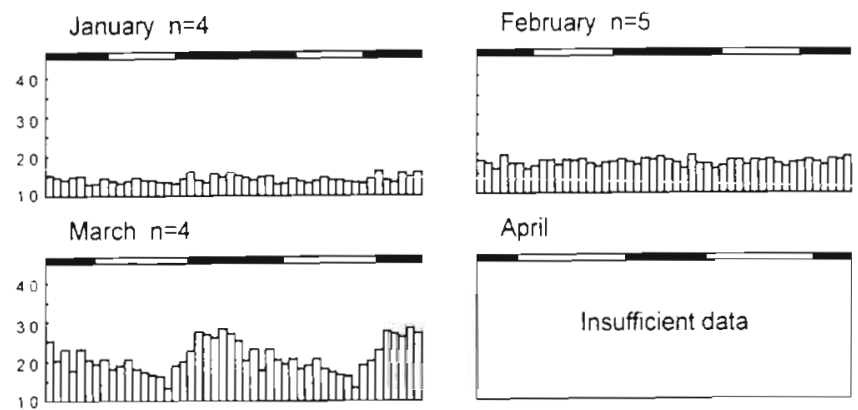

April

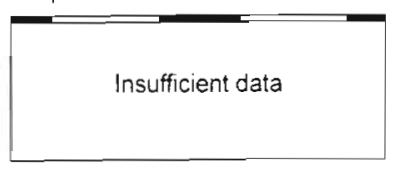

June $n=12$
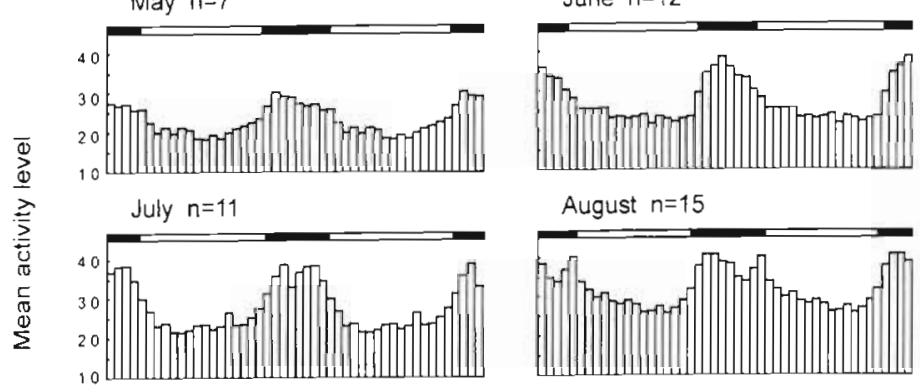

August $n=15$
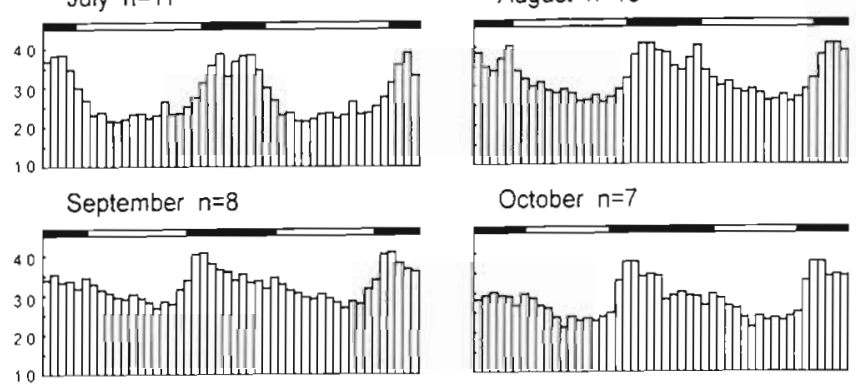

October $n=7$

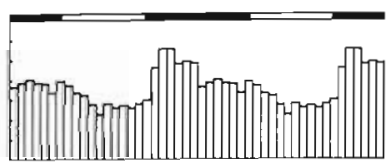

November $n=5$

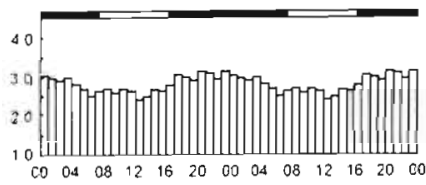

December $n=4$

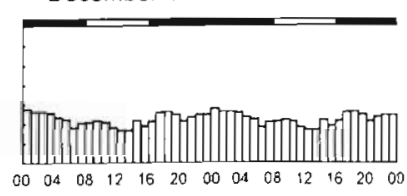

Time of day (h GMT)

Fig. 5. Mean activity level in relation to time of day. Bars in each month represent mean activity of the number of lobsters indicated. Two daily cycles are shown, for clarity. The black and white bars indicate the average periods of night and day, respectively 
mation is available about the incidence of these excursions. The occurrence of more extensive movements in Poole Bay was first evident when adult lobsters were found on the artificial reef within $3 \mathrm{wk}$ of its construction, despite being sited approximately $3 \mathrm{~km}$ from known natural lobster habitat (Jensen et al. 1994). In addition, mark-recapture studies carried out in 1990-92 revealed movement away from the artificial reef: $13 \%$ of lobsters tagged on the reef were recaptured elsewhere in Poole Bay at an average distance of $6.5 \mathrm{~km}$ (Jensen et al. 1994). In the present study, $44 \%$ of tagged lobsters may have left the study site during the monitoring period, based on the number of tags whose electromagnetic signal disappeared, adjusted by an estimate of the tag failure rate. Lobsters that had not been previously tagged at the artificial reef seemed to be more than 3 times as likely to leave the site as those previously tagged there, and which were therefore known to have had a prior association with the site. It appears, therefore, that some lobsters are resident in the artificial reef for prolonged periods, while others are more transient. Since the original times of arrival at the reef are unknown, it is not possible to estimate the distribution of residence times.

A mixture of resident and transient lobsters has been noted in Homarus americanus (Cooper \& Uzmann 1980, Ennis 1984b, Karnofsky et al. 1989b) and various species of spiny lobster (Herrnkind 1980, MacDiarmid et al. 1991). Dybern et al. (1967) noted that some Homarus gammarus in western Sweden occupied the same shelter for weeks, while others often changed shelters. Individuals may change from resident to transient modes at different stages in their life and moult cycles (Ennis 1984b, Atema 1986). Herrnkind (1980) suggested that central place foraging with homing to a particular shelter constituted the typical lifestyle of the Caribbean spiny lobster Panulirus argus, but that nomadism tended to occur where resources such as food, shelter and mates were of low quality or quantity in relation to lobster population density. On this basis, the occurrence of residents and transients in the same area may indicate that transients are competitively inferior, or that their resource requirements or habitat preferences differ from residents. In Homarus spp., as in other benthic crustaceans, changing shelter size requirements during growth may necessitate a search for areas of appropriate substratum type (Howard 1980, Wahle 1992). More information about the nature of longer range excursions away from rocky habitat would probably best be acquired by continuous acoustic tracking with a hydrophone array (e.g. Duggan et al. 1991).

Movements between units of the artificial reef showed marked seasonal variation, with greatest activity in summer and little movement from late December to early May. Activity represented by body movements detected with the tilt switch followed a similar pattern, with maximum values in August and September and minimum values in January and February. Of the measured environmental variables, inter-reef unit movements and activity were most closely related to water temperature, confirming initial indications from a few individuals (Smith et al. 1998). Studies using other methods have indicated that locomotor activity and feeding by lobsters are strongly influenced by seasonal changes in water temperature (Cooper \& Uzmann 1977, 1980, Branford 1979, Ennis 1984a). Karnofsky et al. (1989b) estimated activity of Homarus americanus in a shallow cove in Massachusetts (USA) from the percentage of occasions individuals were seen outside shelter by divers. Maximum activity was recorded in mid-summer and it appeared that lobsters overwintering in the cove became inactive and remained in the same locations for months, although few diving observations were possible in winter owing to storms and ice. Ennis (1984b) made year-round diving observations of lobsters ( $H$. americanus) in Newfoundland. Although no nocturnal observations were made in winter, very low activity levels below about $5^{\circ} \mathrm{C}$ were suggested by the high proportion of shelters occupied by the same lobster on consecutive days. Hallbäck \& Waren (1972) reported anecdotal evidence that Homarus gammarus in western Sweden tended to move to slightly deeper water in autumn and remain within shelters during winter.

In addition to the effect of temperature, activity indicated by the tilt switch was negatively related to midday illumination in the present study, indicating greater activity in turbid or dull conditions. There was also an indication that body movements were positively related to wave height, possibly reflecting passive movement by wave-induced water movement at the seabed. It was anticipated that movement between reef units by lobsters would be reduced during periods of increased wave action, since large waves create oscillatory water movement at the seabed and flume experiments have demonstrated that lobster mobility can be impaired by moving water (Howard \& Nunny 1983). A number of species of lobster move to deeper water in winter, which in some cases may be an avoidance of damaging storm wave action in the shallows (Hallbäck \& Waren 1972, Cooper \& Uzmann 1980, Herrnkind 1980, Ennis 1984a). Inter-reef unit movements in the present study were not significantly related to wave height, perhaps because the maximum bottom orbital velocities experienced were insufficient, or occurred too briefly, to inhibit lobster movement noticeably, or because the greatest wave action occurred in winter, when lobster activity was already reduced by low water temperatures. An influence of 
water movement was suggested, however, by a weak negative relationship between inter-reef unit movements and tidal range, indicating that movement was somewhat reduced during periods of maximum tidal current speeds.

Movements between reef units, which constituted excursions outside shelter (Smith et al. 1998), were predominantly nocturnal, with a peak in movements generally occurring shortly after sunset, and in some months there was a secondary increase in movements before dawn. Locomotor activity was predominantly nocturnal over most of the 7 mo period in which it was possible to assess diel patterns in inter-reef unit movements (May to November). Since measurements of activity with the tilt switch did not rely on lobsters moving between aerials, it was possible to assess diel variation in this measure throughout the year (with the exception of April). In spring, summer and autumn, similar diel patterns in activity were seen as with inter-reef unit movements, but with less abrupt changes around sunset and sunrise in some months. In winter, the diel pattern disappeared as activity diminished throughout the $24 \mathrm{~h}$ period, apparently in response to low water temperatures. A nocturnal activity pattern became evident again in March, at a time of year when water temperature and seabed illumination were increasing, but when inter-reef unit movements were still uncommon. Seasonal variation in the degree of nocturnality in Homarus gammarus was also recorded in an aquarium study (Branford 1979), but in contrast to the present study, the percentage of movements in daylight was least around the vernal equinox and greatest in early to mid-summer.

Findings from the present study and others indicate that the diel timing of lobster movements is largely governed exogenously by changes in light level. The timing of the peak in locomotor activity and the portion of the $24 \mathrm{~h}$ period in which lobsters were mobile varied in accordance with seasonal changes in the times of sunset and sunrise. In autumn and early winter, when illumination at the sea bed was reduced by increased turbidity, diurnal movements were more common than in summer. Diurnal movements by lobsters at low light levels have also been observed by diving (Hallbäck \& Waren 1972, Cooper \& Uzmann 1980, Spanier \& Almog-Shtayer 1992, Lawton \& Lavalli 1995). Trawling and video surveys of the Norway lobster Nephrops norvegicus indicate that emergence from burrows occurs within a particular range of low light intensity, the diel timing of which varies with depth (Chapman 1980). However, there seem to be some contexts in which clawed and spiny lobsters are mobile despite high prevailing light levels, such as during long range migration (Kanciruk \& Herrnkind 1978), reproductive activity (Lipcius et al. 1983, MacDiarmid et al. 1991) and shelter competition (Lawton 1987).
The apparent response to ambient light levels or changes in level does not exclude the possibility of endogenous circadian rhythms in readiness to undertake excursions, or in other aspects of behaviour. For example, an endogenous circadian rhythm has been identified in the larval release behaviour of ovigerous female Homarus gammarus (Branford 1978) and Nephrops norvegicus displays activity rhythms under constant conditions in the laboratory which may be related to burrow excavation and maintenance in nature (Chapman 1980). In some months during the present study, activity indicated by the tilt switch began to increase from the afternoon minimum well before sunset and the onset of movements between reef-units. Increased activity prior to nocturnal excursions from shelter has been noted in other species of lobster (Cooper \& Uzmann 1980; Herrnkind 1980) and may reflect endogenously controlled variation in responsiveness to environmental cues, such as a reduction in light intensity.

The present study illustrates the potential of electromagnetic telemetry for making long-term measurements of lobster activity in situ and has identified major seasonal and diel changes in activity. Since locomotor activity is one of the major behavioural components of catchability in baited traps (Miller 1990), these findings suggest that there are significant systematic changes in the relationship between fishing effort and fishing mortality, which should be incorporated into census methods using traps. Simulation models of the capture process for Homarus gammarus have largely concentrated so far on 'gear saturation' resulting from behavioural interactions between animals in and around traps (Addison \& Bannister 1998). More realistic models that can be used to predict the effects of changes in fishing effort on stock abundance and yield per recruit require an estimate of the proportion of the stock encountering baited traps during fishing sessions under different conditions (Addison \& Bell 1997). The small, experimental artificial reef used in the present study did not support a sufficiently large population of lobsters to obtain this type of information, but it would be possible to conduct an electromagnetic telemetry study on a larger scale in natural habitat, permitting a greater number of lobsters to be monitored simultaneously over a larger area. Larger sample sizes would also allow more powerful statistical analysis of subsidiary environmental effects on activity and of lobster attributes thought to influence catchability, such as size, sex and moult state (Miller 1990).

Acknowledgements. This study was funded by the Ministry of Agriculture Fisheries and Food. We are grateful for support and advice from R. C. A. Bannister and J. T Addison (CEFAS Lowestoft), and assistance given in the field by J. J. Mallinson, F. Elston and volunteer divers. 


\section{LITERATURE CITED}

Addison JT, Bannister RCA (1998) Quantifying potential impacts of behavioral factors on crustacean stock monitoring and assessment: modeling and experimental approaches. In: Jamieson GS, Campbell A (eds) Proceedings of the North Pacific Symposium on Invertebrates Stock Assessment and Management. Can Spec Publ Fish Aquat Sci 125:167-177

Addison JT, Bell MC (1997) Simulation modelling of capture processes in trap fisheries for clawed lobsters. Mar Freshwat Res 48:1035-1044

Arnold GP, Greer Walker M. Holford BH (1990) Fish behaviour: achievments and potential of high-resolution sectorscanning sonar. Rapp P-V Réun Cons Int Explor Mer 189: $112-122$

Atema J (1986) Review of sexual selection and chemical communication in the lobster Homarus americanus. Can J Fish Aquat Sci 43:2283-2290

Begon M, Harper JL, Townsend CR (1990) Ecology, 2nd edn Blackwell Scientific Publishers, Boston

Branford JR (1978) The influence of daylength, temperature and season on the hatching rhythm of Homarus gammarus. J Mar Biol Assoc UK 58:639-658

Branford JR (1979) Locomotor activity and food consumption by the lobster Homarus gammarus. Mar Behav Physiol 6: $13-24$

Chapman CJ (1980) Ecology of juvenile and adult Nephrops. In: Cobb JS, Phillips BF (eds) The biology and management of lobsters. Vol 2. Ecology and management. Academic Press, New York, p 143-178

Chapman CJ, Johnstone ADF, Rice AL (1975) The behaviour and ecology of the Norway lobster, Nephrops norvegicus (L.). In: Barnes $\mathrm{H}$ (ed) Proceedings of the 9th European Marine Biological Symposium. Aberdeen University Press, Aberdeen, p 59-74

Collins KJ (1996) Development of an electromagnetic telemetry system for tracking lobsters on an artificial reef. In Baras E, Philippart JC (eds) Underwater biotelemetry. Proceedings of the first conference and workshop on fish telemetry in Europe. University of Liège, Belgium p 225-234

Collins KJ, Jensen AC (1992) Acoustic tagging of lobsters on the Poole Bay artificial reef. In: Priede IG, Swift SM (eds) Wildlife telemetry. Remote monitoring and tracking of animals. Ellis Horwood, London, p 354-358

Collins KJ, Jensen AC, Lockwood APM (1991) Artificial reets using coal-fired power station wastes constructively for fishery enhancement. Oceanol Acta 11:225-229

Cooper RA, Uzmann JR (1977) Ecology of juvenile and adult clawed lobsters, Homarus americanus, Homarus gammarus, and Nephrops norvegicus. Circ - CSIRO, Div Fish Oceanogr (Aust) 7:187-208

Cooper RA, Uzmann JR (1980) Ecology of juvenile and adult Homarus. In: Cobb JS, Phillips BF (eds) The biology and management of lobsters. Vol 2. Ecology and management. Academic Press, New York, p 97-142

Duggan RE, Pringle JD, Webber DM, O'Dor RK (1991) Tracking lobster movement using ultrasonic transmitters. J Shellfish Res 10:282

Dybern BI (1973) Lobster burrows in Swedish waters. Helgol Wiss Meeresunters 24:401-414

Dybern BI, Jacobsson L, Hallbäck H (1967) On the habitat behaviour of the lobster (Homarus vulgaris) in Swedish waters. ICES CM 1967/K:3

Earle MD, Bishop JM (1984) A practical guide to ocean wave measurement and analysis. Endeco Inc, Marion, MA.
Ennis GP (1984a) Small-scale seasonal movements of the American lobster Homarus americanus. Trans Am Fish Soc 113:336-338

Ennis GP (1984b) Territorial behavior of the American lobster Homarus americanus. Trans Am Fish Soc 113:330-335

Gamble JC (1984) Diving. In: Holme NA, McIntyre AD (eds) Methods for the study of marine benthos. IBP handbook 16. Blackwell Scientific Publications, Oxford, p $99-139$

Greenwood JJD (1996) Basic techniques. In: Sutherland WJ (ed) Ecological census techniques: a handbook. Cambridge University Press, Cambridge, p 11-110

Gulland JA (1983) Fish stock assessment. A manual of basic methods. John Wiley \& Sons, Chichister

Hall SJ, Basford DJ, Robertson MR, Raffaelli DG, Tuck 1 (1991) Patterns of recolonization and the importance of pit-digging by the crab Cancer pagurus in a subtidal sand habitat. Mar Ecol Prog Ser 72:93-102

Hallbäck H, Waren A (1972) Food ecology of the lobster, Homarus vulgaris, in Swedish waters. Some preliminary results. ICES CM 1972:K29

Herrnkind WF (1980) Spiny lobsters: patterns of movement In: Cobb JS, Phillips BF (eds) The biology and management of lobsters. Vol. 1. Physiology and behavior. Academic Press, New York, p 349-408

Herrnkind WF, VanDerwalker JA, Barr L (1975) Population dynamics, ecology and behavior of spiny lobsters, Panulirus argus, of St. John, U.S. V.I.. (IV) habitation, patterns of movement and general behavior. Bull Nat Hist Mus LA County 20:31-45

Hines $\mathrm{AH}$, Wolcott TG, González-Gurriarán E, GonzálezEscalante JL, Freire J (1995) Movement patterns and migrations in crabs: telemetry of juvenile and adult behavior in Callinectes sapidus and Maja squinado. J Mar Biol Assoc UK 75:27-42

Howard AE (1980) Substrate controls on the size composition of lobster (Homarus gammarus) populations. J Cons Int Explor Mer 39:130-133

Howard AE, Nunny RS (1983) Effects of near-bed current speeds on the distribution and behaviour of the lobster, Homarus gammarus (L.). J Exp Mar Biol Ecol 71:27-42

Jensen AC, Collins KJ, Free EK, Bannister RCA (1994) Lobster (Homarus gammarus) movement on an artificial reef: the potential use of artificial reefs for stock enhancement. Crustaceana 67:198-211

Kanciruk P, Herrnkind WF (1978) Mass migration of spiny lobster, Panulirus argus (Crustacea: Palinuridae): behavior and environmental correlates. Bull Mar Sci 28 $601-623$

Karnofsky EB, Atema J, Elgin RH (1989a) Field observations of the social behaviour, shelter use, and foraging in the lobster, Homarus americanus. Biol Bull 176:239-246

Karnofsky EB, Atema J, Elgin RH (1989b) Natural dynamics of population structure and habitat use of the lobster, Homarus americanus, in a shallow cove. Biol Bull 176: $247-256$

Lawton P (1987) Diel activity and foraging behaviour of juvenile American lobsters, Homarus americanus. Can J Fish Aquat Sci 44:1195-1205

Lawton P, Lavalli KL (1995) Postlarval, juvenile, adolescent, and adult ecology. In: Factor JR (ed) Biology of the lobster Homarus americanus. Academic Press, San Diego, p 47-88

Lipcius RN, Edwards ML, Herrnkind WF, Waterman SL (1983) In situ mating behavior of the spiny lobster Panulirus argus. J Crust Biol 3:217-222

Lovewell SR, Howard AE, Bennett DB (1988) The effectiveness of parlour pots for catching lobsters (Homarus gam- 
marus (L.)) and crabs (Cancer pagurus L.). J Cons Int Explor Mer 44:247-252

Lund WA, Lockwood RC (1970) Sonic tag for large decapod crustaceans. J Fish Res Board Can 27:1147-1151

MacDiarmid AB, Hickey B, Maller RA (1991) Daily movement patterns of the spiny lobster Jasus edwardsii (Hutton) on a shallow reef in northern New Zealand. J Exp Mar Biol Ecol 147:185-205

Martin P, Bateson P (1993) Measuring animal behaviour. An introductory guide, 2nd edn. Cambridge University Press, Cambridge

Miller RJ (1990) Effectiveness of crab and lobster traps. Can J Fish Aquat Sci 47:1228-1251

Neter J, Kutner MH, Nachsheim CJ, Wasserman W (1996) Applied linear statistical models, 4 th edn. Irwin, Chicago

O'Neill DJ, Cobb JS (1979) Some factors influencing the outcome of shelter competition in lobsters (Homarus americanus). Mar Behav Physiol 6:33-45

Ramm DC (1980) Electromagnetic tracking of rock lobsters ( $\mathrm{Ja}$ sus novaehollandiae). Aust J Mar Freshwat Sci 31:263-269

Smith IP, Collins KJ, Jensen AC (1998) Movement and activity patterns of the European lobster, Homarus gammarus, revealed by electromagnetic telemetry. Mar Biol 132:611-623

Editorial responsibility: Otto Kinne (Editor), Oldendorf/Luhe, Germany
Spanier E. Almog-Shtayer G (1992) Shelter preferences in the Mediterranean slipper lobster: effects of physical properties. J Exp Mar Biol Ecol 164:103-116

Stone RP, O'Clair CE, Shirley TC (1992) Seasonal migration and distribution of female red king crabs in a southeast Alaskan estuary. J Crust Biol 12:546-560

Sutherland WJ (1996) From individual behaviour to population ecology. Oxford University Press, Oxford

Urquhart GG, Smith GW (1992) Recent developments of a fixed hydrophone array system for monitoring movements of aquatic animals. In: Priede IG, Swift SM (eds) Wildlife telemetry. Remote monitoring and tracking of animals. Ellis Horwood, London, p 342-353

van der Meeren GI (1997) Preliminary acoustic tracking of native and transplanted European lobsters (Homarus gammarus) in an open sea lagoon. Mar Freshwat Res 48: 915-921

Wahle RA (1992) Substratum constraints on body size and the behavioral scope of shelter use in the American lobster. J Exp Mar Biol Ecol 159:59-75

Wolcott TG (1995) New options in physiological and behavioural ecology through multichannel telemetry. J Exp Mar Biol Ecol 193:257-275

Submitted: January 22, 1999; Accepted: April 9, 1999 Proofs received from author(s): August 20, 1999 